\title{
As histórias efêmeras e evocativas das danças cubanas
}

\author{
Elizabeth Schwall \\ Northern Arizona University \\ Igor Lemos Moreira \\ Universidade do Estado de Santa Catarina
}

\begin{abstract}
Resumo
Em entrevista concedida a Igor Lemos Moreira, a historiadora estadunidense Elizabeth Schwall reflete sobre o papel da dança cubana no contexto revolucionário da ilha. Especialista na interface entre artes e política nas Américas, Schwall discorre sobre aspectos teórico-metodológicos de estudas as artes performances na historiografia, os diferentes processos que envolveram a institucionalização de dança pelo governo revolucionário cubano e as histórias interconectadas entre exilados e artistas que apoiadores da revolução. Ao longo da entrevista, realizada remotamente, percebe-se que além de um campo profícuo a historiografia da arte, o estudo da dança cubana no século XX possibilita refletir acerca das conexões globais e entrelaçadas entre política, sociedade, arte e indivíduos.
\end{abstract}

Palavras-Chave: dança; artes cubanas; revolução; historiografia; arte e política.

A Revolução Cubana e seus desdobramentos no tempo presente têm se destacado como um importante campo de pesquisadores dedicados aos estudos latino-americanos e caribenhos. Nos últimos anos, observasse o surgimento de uma série de novos pesquisadores dedicados ao estudo de Cuba, o que trouxe uma grande renovação na compreensão da revolução como momento de efervescência cultural e inauguração de novas relações temporais no continente americano. Um dos principais campos interdisciplinares deste campo discute as artes no contexto revolucionário, com destaque para o cinema, a música e a dança.

Elizabeth Schwall é historiadora com especialização em estudos latino-americanos e caribenhos, com ênfase na dança cubana do século XX. Dedicada à hipótese de que a arte desempenhou um papel fundamental na vida política e social ao longo do século passado, Schwall publicou recentemente seu primeiro livro, intitulado Dancing with the Revolution: 
Power, Politics, and Privilege in Cuba (University of North Carolina Press, 2021), além de diversos artigos sobre dança em Cuba e no exterior. Atualmente é professora assistente no Departamento de História da Northern Arizona University e anteriormente foi bolsista no Center for Ballet and the Arts da New York University (2018) e pós-doutorada em estudos de dança na Northwestern University (2016-2018).

Conduzida digitalmente por Igor Lemos Moreira (Universidade do Estado de Santa Catarina), a entrevista abordar alguns questionamentos, conclusões e contribuições de Elizabeth Schwall para o campo da arte cubana.

Igor Lemos Moreira: Elizabeth Schwall, poderia falar sobre sua trajetória acadêmica?

Elizabeth Schwall: Na graduação, comecei a procurar uma maneira de combinar minhas paixões pela dança e história política. Inicialmente, minhas experiências como dançarina influenciaram a minha pesquisa histórica. Por exemplo, apresentei uma reconstrução de L'après-midi d'un faune, de Vaslav Nijinsky (1912), e um solo dos anos 1970 de Ze'eva Cohen, o que me levou a pensar sobre as histórias embutidas na dança. Simultaneamente, em um seminário de graduação sobre intelectuais na América Latina coministrado pelo historiador Jeremy Adelman e o estudioso literário Arcadio Díaz-Quiñones, li o discurso de Fidel Castro, de junho de 1961, "Palavras aos intelectuais", onde era mencionado as conquistas recentes de companhias cubanas de balé e dança moderna. Fiquei intrigada. Eu não poderia imaginar um líder dos Estados Unidos mencionando dança profissional (muito menos qualquer artista) em um discurso importante. Percebi que Cuba era um poderoso estudo de caso para examinar o papel da dança (e das artes em geral) na história política. Isso me levou a começar a pesquisar a dança cubana, e escrevi um ensaio sobre como e por que Fidel Castro e a Revolução Cubana de 1959 apoiaram o balé. Em seguida, escrevi um trabalho de conclusão de curso que comparava as trajetórias do balé e da dança moderna na Cuba dos anos 1960.

Para minha tese de doutorado, que se tornou a base para meu novo livro, examinei o balé, a dança moderna e a dança folclórica em Cuba. Influenciada por historiadores como Alejandro de la Fuente ${ }^{1}$ e Jennifer Lambe ${ }^{2}$, percebi que, para entender o que aconteceu depois de 1959, precisava analisar a evolução política e a dança nas décadas anteriores. Portanto, minha análise da dança começa em 1930 e termina em 1990, quando as coisas mudaram consideravelmente na cultura, política e economia cubana como resultado de uma crise causada pela queda da União Soviética e o início do chamado Período Especial em Tempos de Paz em Cuba. Embora minhas perguntas, argumentos, período de tempo e

\footnotetext{
${ }^{1}$ DE LA FUENTE, 2001.

2 LAMBE, 2017.
} 
protagonistas tenham mudado ou se expandido ao longo dos anos, continuei interessada em entender como a política moldava a dança e como os dançarinos intervinham em projetos políticos.

ILM: Você recentemente publicou Dancing with the Revolution: Power, Politics, and Privilege in Cuba, pela UNC Press, no qual examina o papel da dança no contexto revolucionário cubano. Os estudos sobre a política cultural cubana são extensos, especialmente sobre música, cinema e literatura, mas seu livro analisa uma expressão artística que não é comumente discutida. Você poderia nos falar sobre o papel da dança no estabelecimento da revolução? Em que diferia do que o governo tentava construir em outros setores, como no Instituto Cubano del Arte e Industria Cinematográficos?

ES: Eu devo muito a excelentes estudos de outras formas de arte como música, cinema, teatro e literatura ${ }^{3}$, que me inspiraram a incluir a dança nas discussões sobre a Revolução. Como outras produções artísticas, a dança tornou-se um meio de projetar certas imagens de Cuba e da Revolução para o público internacional.

O balé, a dança moderna e a dança folclórica projetavam algo diferente sobre a nação. O balé, que considero ter se tornado uma expressão da branquitude e da cultura de elite em Cuba tanto antes quanto depois de 1959, projetou ideias frequentemente carregadas de iluminação, elegância e educação. Assim como os membros do Ballet Nacional de Cuba rivalizavam com centros de balé históricos e contemporâneos como França, Rússia e Nova York, os comentaristas cubanos viam o balé como um antídoto para o subdesenvolvimento histórico. Além disso, como todos os cubanos tinham maior acesso a apresentações de balé, que eram baratas ou gratuitas (ou se viam forçados a assistir a demonstrações de balé em fábricas, escolas e parques), o outrora passatempo da elite tornou-se um patrimônio nacional e, portanto, evidenciou ostensivamente a democratização das artes em Cuba revolucionária. A dança moderna, como o nome indica, articulava modernidade e inovação de vanguarda por meio de uma estética politizada. Os dançarinos modernos priorizaram o antirracismo revolucionário, em particular, e criaram um estilo nacional que reconfigurou as técnicas de dança moderna estrangeiras (e implicitamente brancas) integrando elementos da cultura afrocubana. A primeira companhia profissional de dança moderna (hoje conhecida como Danza Contemporánea de Cuba), fundada em 1959 pelo coreógrafo cubano Ramiro Guerra, tornouse a primeira companhia de dança profissional na ilha com membros de diferentes etnicidades. Guerra escolheu cuidadosamente o mesmo número de pessoas que ele considerou dançarinos brancos, mulatos e negros, que então realizaram obras que

\footnotetext{
3 Ver: GUERRA, 2012; MIRABAL; VELAZCO, 2013; MOORE, 2006; SERRA, 2007.
} 
dramatizaram a integração racial. Por fim, a dança folclórica projetou discursos populistas da Revolução à medida que companhias como o Conjunto Folklórico Nacional, com sede em Havana, fundado em 1962, encenavam danças populares e rituais afro-cubanos. Nos primeiros anos, a maioria dos membros da companhia folclórica vinha da classe trabalhadora e era de ascendência africana. O governo exportou a companhia para mostrar a suposta erradicação dos preconceitos raciais e de classe, já que os afro-cubanos de classe baixa representavam a nação no cenário mundial.

Mesmo quando dançarinos contribuíram para o perfil internacional da Revolução, eles também perturbaram os ideais revolucionários, especialmente sobre gênero e sexualidade. $\mathrm{Na}$ Cuba revolucionária, como em outros lugares do mundo, as pessoas presumiam que a dança (e especialmente o balé) era uma arte feminina e que os bailarinos arriscavam a efeminação e a homossexualidade. No entanto, enquanto o governo encarcerava escritores, músicos e cineastas notáveis que foram acusados de homossexualidade, os dançarinos continuaram trabalhando, na melhor das hipóteses, ou foram deixados de lado na pior. É interessante questionar, por exemplo, por que o governo permitiu que o Ballet Nacional de Cuba fizesse uma turnê anualmente, apesar das deserções de alto nível, muitas vezes por homens presumivelmente gays? Por que o governo não fechou a companhia de dança moderna após a censura de 1971 a um trabalho provocativo que os burocratas chamavam de pornográfico? Por que o governo não retirou os fundos do Conjunto Folklórico Nacional depois que figuras fundacionais reconheceram ou foram acusadas de manter relações entre pessoas do mesmo sexo? Embora as respostas a essas perguntas possam ser complexas e elusivas, os documentos existentes fornecem algumas explicações possíveis. Por exemplo, com base em memorandos internos, descobri que líderes de dança com conexões, como Alicia Alonso (a famosa bailarina e apoiadora revolucionária) ou Lorna Burdsall (uma importante dançarina moderna e esposa do notável revolucionário Manuel Piñeiro), usavam seus privilégios para proteger os companheiros dançarinos e promover suas causas de dança. Da mesma forma, os documentos sugerem que, à medida que os dançarinos conquistavam perfis internacionais, os burocratas viam os benefícios superando os riscos em permitir que os dançarinos continuassem a impressionar os observadores estrangeiros. Apesar de tudo, os dançarinos desfrutavam de graus únicos de controle sobre suas carreiras e arte, apesar da ameaça da homofobia revolucionária.

Embora o governo recrutasse dançarinos, como cineastas, músicos, atores e escritores, para contribuir com o projeto revolucionário e os dançarinos trabalhassem em instituições nacionalizadas, a dança permaneceu um domínio com relativamente menos supervisão em comparação com outras formas de arte. O governo parecia ter problemas para entender completamente a dança efêmera e não verbal, e assim os burocratas delegaram as operações do dia a dia e a criação de conteúdo a especialistas. Além disso, a dança pode ter 
parecido menos ameaçadora ou potencialmente subversiva do que o filme ou a ficção devido à sua falta de fixidez e perfil metafórico. O conteúdo político das produções de dança variava de um apoio vibrante à Revolução a divergências não-intencionais, especialmente de ortodoxias sociais, quando os dançarinos encenavam meditações ambíguas sobre justiça racial ou relações entre pessoas do mesmo sexo. Então, em suma, havia muito que os dançarinos compartilhavam com outros artistas em termos de contribuição para projetos revolucionários, mas descobri que os dançarinos também diferiam de seus colegas em outras mídias, pois pareciam ter relativamente mais poder sobre seus corpos e carreiras.

ILM: A dança, como a música, é uma arte efêmera que depende da relação com o público e que só pode ser analisada quando existe algum tipo de registro. Em sua pesquisa, você tenta contornar esse processo, usando documentos governamentais, cartas, imprensa, programas performáticos, filmes, esquetes e fotografias. Qual o principal desafio em lidar com a efemeridade dessas práticas artísticas na pesquisa acadêmica?

ES: Embora sem dúvida um desafio, analisar as danças do passado oferece uma oportunidade única para refletir sobre a história de forma mais ampla. Um movimento de dança, como qualquer evento histórico, desaparece com a realização. Registros textuais e visuais fornecem pistas sobre a dinâmica, participantes, sons e sentimentos em performances anteriores. Considere, por exemplo, memorandos do governo sobre fantasias, cartas escritas por um coreógrafo sobre os desafios de montar um novo trabalho, imprensa sobre um dueto poderoso ou programas de performance com detalhes sobre o significado e objetivo de uma performance particular. Cada um desses registros textuais fornece insights inestimáveis. Além disso, tenho a sorte de haver esquetes, fotografias ou filmes de figurinos de várias performances que estudo do passado recente. Com essas fontes visuais, presto muita atenção aos detalhes coreográficos - como os corpos se movem no espaço e como se relacionam uns com os outros - e tento examinar o que essas declarações cenestésicas revelam sobre seu contexto histórico. Acredito que historiadores sem interesse em performance podem aprender com essa abordagem da dança para a história. Quando estudiosos analisam mulheres marchando em um protesto ou funcionários trabalhando pesadamente em uma fábrica, por exemplo, eles podem fazer uma pausa para procurar detalhes sobre coreografias políticas e sociais para obter novos insights sobre ações e consequências históricas.

Dito isso, inevitavelmente há apresentações sobre as quais eu gostaria de saber mais ou mesmo ver. Pode ser difícil descobrir o que um coreógrafo pretendia e o que o público entendia de danças metafóricas não verbais. Por exemplo, Ramiro Guerra escreveu extensivamente sobre sua coreografia, mas nunca consigo compreender totalmente o escopo 
teatral, o conteúdo dramático, as intenções políticas e o impacto visual de peças canônicas como Orfeo Antillano (1964) sem filmagem e talvez um diário em que Guerra detalhou seu processo criativo. Mesmo que tais materiais inestimáveis surgissem, eu ainda me perguntaria sobre os suspiros, aplausos, respeito silencioso e comentários abafados do público durante as apresentações na década de 1960. Em suma, as danças do passado, assim como os pensamentos e ações de qualquer figura histórica, permanecem envoltas em algum mistério. Identificar significados dessas entidades elusivas, uma tarefa que às vezes pode ser frustrante ou impossível, mais me motiva do que me impede.

ILM: Sua pesquisa mostra que apesar de uma imagem de governo "unificador" das artes, a performance de dança em Cuba no contexto revolucionário foi bastante diversa, envolvendo gêneros como balé, dança moderna e dança folclórica. Além disso, dançarinos e coreógrafos cubanos interagiram com artistas de outras localidades. Você poderia falar sobre essa interação entre diferentes gêneros e nacionalidades na dança cubana?

ES: Como você observou, comparo diferentes gêneros de dança e como os burocratas culturais e líderes políticos os trataram de maneira diferente. Documentos oficiais, como memorandos e orçamentos, bem como gestos mais simbólicos, como turnês internacionais totalmente financiadas ou membros da audiência de alto nível, mostram níveis díspares de apoio do Estado. Em última análise, o balé, que representava branquitude e gosto elitista no imaginário cubano, teve o maior apoio, enquanto a dança moderna e folclórica, que tinha dançarinos mais diversificados e se baseava fortemente na cultura popular afro-cubana, tinha relações mais ambivalentes com o Estado. Essa realidade revela que os discursos revolucionários sobre igualdade de classe e raça tinham limitações na prática.

Existem muitos exemplos do privilégio balético. Por exemplo, Fidel Castro visitou pessoalmente o líder do balé Fernando Alonso para oferecer um subsídio considerável, que foi oficialmente protegido por lei em 1960. Os bailarinos se apresentavam mais no exterior, o que trouxe benefícios materiais consideráveis na forma de honorários e diárias em moeda. Castro também comparecia com frequência a apresentações de balé, especialmente com ilustres convidados internacionais. Evidências de poder balético se manifestaram até mesmo em 2016, quando o presidente dos EUA, Barack Obama, visitou Cuba. Ele fez seu histórico discurso televisionado ao povo cubano no Gran Teatro Alicia Alonso, encontrou-se com Alonso naquele dia e Alonso ouviu o discurso enquanto estava sentado a algumas cadeiras do presidente cubano Raúl Castro. Nenhum outro líder de dança, pelo que eu poderia dizer, conheceu Obama ou compareceu a seu discurso de forma tão proeminente. Enquanto isso, a dança moderna tinha apoio, mas menos do que o balé. Por exemplo, embora Castro tenha elogiado os dançarinos modernos em seu discurso "Palavras aos Intelectuais" de 1961, os 
burocratas culturais negaram aos dançarinos modernos uma importante oportunidade de apresentação internacional em 1964 e os censuraram em 1971. Castro só viu uma apresentação de dança moderna pela primeira vez no início dos anos 1970. A dança folclórica teve menor apoio nas décadas após 1959. Não houve subsídio formal do governo para o Conjunto Folklórico Nacional até depois da estreia extremamente bem-sucedida da companhia em 1963. Embora a companhia se apresentasse no exterior em 1964, a próxima turnê só ocorreu em 1970. Documentos oficiais do governo revelam que preconceitos raciais influenciaram no apoio menos substancial à companhia, que tinha uma maioria de dançarinos negros e apresentava principalmente a cultura popular afro-cubana no palco. As diferenças salariais entre dançarinos dos diferentes gêneros confirmam absolutamente que existiam hierarquias na Cuba socialista.

Embora grande parte da minha pesquisa se concentre nas divisões de gênero, é importante notar que essas linhas construídas eram na verdade bastante fluidas e porosas, pois dançarinos, coreógrafos e professores trabalharam em diferentes gêneros ao longo de suas carreiras. Por exemplo, os dançarinos modernos tiveram (e ainda fazem) aulas de balé e dança folclórica como parte de seu treinamento. lleana Farrés, que começou sua carreira como dançarina moderna, acabou ingressando no Ballet Nacional de Cuba e se tornou uma notável professora de balé. O dançarino moderno Santiago Alfonso começou a coreografar para o Conjunto Folklórico Nacional na década de 1960 e Ramiro Guerra fez o mesmo no final dos anos 1970 e início dos anos 1980. O dançarino moderno fundador Alberto Méndez tornouse um coreógrafo de balé notável. O coreógrafo de balé Alberto Alonso formou o Conjunto Experimental de Danza de la Habana, que buscava mesclar balé, dança moderna, dança folclórica e dança popular em um repertório eclético. Víctor Cuéllar começou sua carreira trabalhando com Alberto Alonso e acabou se tornando um notável dançarino e coreógrafo moderno. Portanto, embora as ideologias de classe e raça alimentassem diferenças materiais muito reais entre os gêneros, as instituições e os profissionais da dança interagiam regularmente ao longo dessas linhas construídas.

Quanto aos dançarinos de diferentes origens nacionais, a União Soviética tornou-se um parceiro de dança politicamente vantajoso à medida que Cuba estabelecia relações políticas e comerciais com o bloco socialista. Os bailarinos soviéticos viajaram para Cuba na década de 1960 para preencher uma lacuna deixada pelos bailarinos americanos que haviam colaborado com os "Alonsos" no final dos anos 1940 e 1950. Em particular, Cuba carecia de dançarinos masculinos locais imediatamente após 1959, o que levou a dançarinos soviéticos como Azari Plisetski estabelecerem uma parceria com Alicia Alonso e ajudaram a treinar uma nova geração de dançarinos de balé. Além disso, os cubanos convidaram tecnocratas soviéticos para aconselhá-los no desenvolvimento de um sistema de treinamento de balé no país na década de 1960. No entanto, na década de 1970, o aconselhamento soviético 
diminuiu. Plisetski, por exemplo, deixou Cuba em 1973. Naquela época, a primeira geração de dançarinos cubanos formada após a Revolução havia atingido a maturidade e ingressado no Ballet Nacional de Cuba. Jorge Esquivel tornou-se o primeiro homem cubano a fazer parceria com Alicia. Embora as conexões de balé entre Cuba e a União Soviética tenham continuado além daquele ano, foram particularmente intensas nos anos 1960 até o início dos anos $1970^{4}$.

Os bailarinos não estavam sozinhos na colaboração com colegas estrangeiros; dançarinos modernos e folclóricos, por exemplo, trabalharam com colegas mexicanos. Os dançarinos modernos mexicanos Waldeen, Elena Noriega, Manuel Hiram e Rodolfo Reyes contribuíram para a construção de inúmeras instituições de dança cubana. Waldeen passou o menor tempo em Cuba, embora tenha tido uma posição de alto impacto como a primeira diretora do departamento de dança moderna da Escuela Nacional de Arte (ENA). Noriega e Hiram passaram anos na década de 1960 ensinando e coreografando para o Conjunto Nacional de Danza Moderna (hoje Danza Contemporánea de Cuba). Com base em suas experiências no México, Noriega e Hiram apoiaram seus colegas cubanos enquanto sistematizavam uma nova técnica exclusivamente cubana. Rodolfo Reyes também trabalhou brevemente com dançarinos modernos, mas, principalmente, foi cofundador do Conjunto Folklórico Nacional com Rogelio Martínez Furé. Como com os soviéticos, havia afinidades políticas que facilitavam as colaborações entre cubanos e mexicanos. Os dançarinos mexicanos que acabaram em Cuba tinham tendências de esquerda e estavam ansiosos para construir novas instituições de dança na ilha. Além disso, o México teve sua própria revolução (1910-20) e um projeto cultural pós-revolucionário, que deu aos dançarinos um repertório político e prioridades coreográficas para recorrer enquanto estiveram em $\mathrm{Cuba}^{5}$.

Os cubanos não trabalharam apenas com dançarinos soviéticos e mexicanos politicamente convenientes, mas também com dançarinos dos Estados Unidos, especialmente Lorna Burdsall e Elfriede ("Elfrida") Mahler, mas também Morris Donaldson, Muriel Manings e Alma Guillermoprieto, entre outros, ao longo das décadas. Os expatriados norte-americanos, carinhosamente conhecidos como Lorna e Elfrida, viveram décadas em Cuba e se tornaram figuras fundamentais da dança moderna. Ramiro Guerra escolheu Lorna para dançar com sua nova companhia de dança moderna durante uma audição inicial em 1959, e ela rapidamente começou a ensinar e coreografar para a companhia também. Ela também acabou dirigindo o grupo e advogando em seu nome no início dos anos 1970. Ela também desempenhou um papel importante na formação da pedagogia da dança como professora e conselheira nacional de currículo e, em 1981, formou a Así Somos, a primeira

\footnotetext{
${ }^{4}$ SCHWALL, 2018.

5 SCHWALL, 2017.
} 
pequena companhia experimental de dança teatral em $\mathrm{Cuba}^{6}$. Elfrida também dançou brevemente na companhia de dança moderna de Guerra, dirigiu o departamento de dança moderna da ENA depois de Waldeen, ensinou e desenvolveu um currículo para o movimento de aficionados ("amadores") e desenvolveu o ensino de dança moderna e uma companhia profissional em Guantánamo. Donaldson coreografou várias obras para o Conjunto Nacional de Danza Moderna em 1969. Manings foi professor convidado em 1970 e 1984, e a mexicana Guillermoprieto também ensinou como convidado em 19707. Embora Burdsall, Mahler, Donaldson e Manings tenham nascido nos Estados Unidos imperialistas, Burdsall casou-se com um revolucionário importante; Mahler era uma comunista devotada; Donaldson foi um coreógrafo afro-americano que denunciou o racismo nos Estados Unidos; e Manings tinha inclinações de esquerda e simpatias revolucionárias. Portanto, sua presença em Cuba fazia sentido político. Todos eles contribuíram para o desenvolvimento da dança moderna ao longo das décadas.

Apesar das muitas contribuições notáveis desses colaboradores estrangeiros, o nacionalismo manteve os cubanos na frente e no centro. Os cubanos descrevem Plisetski, por exemplo, aprendendo tanto com os cubanos quanto eles com ele, e afirmam que a escola cubana de balé é decididamente diferente da escola soviética. Rodolfo Reyes teve um desentendimento com seus colaboradores cubanos no final dos anos $1960^{8}$. Lorna Burdsall ${ }^{9}$ teve que promover e proteger seu legado, pois foi um tanto marginalizada nos estudos cubanos sobre o desenvolvimento da dança moderna nacional. Portanto, estrangeiros apoiaram, mas não definiram os desenvolvimentos da dança cubana.

Vale ressaltar que os enumerados acima são apenas alguns exemplos de colaboradores internacionais. Por exemplo, dançarinos de balé porto-riquenhos como Silvia Marichal, Otto Bravo e José Parés também contribuíram para o desenvolvimento do balé cubano. O chileno Patricio Bunster e a uruguaia Teresa Trujillo coreografaram para o balé cubano e dançarinos modernos, respectivamente. Os cubanos também trabalharam com estrangeiros no exterior, como quando Alberto Alonso desenvolveu Carmen na União Soviética com a bailarina Maya Plisetskaya ou quando Alicia encenou sua versão de Giselle em Paris em 1972. Em outras palavras, há muitas outras histórias para contar sobre dançarinas cubanas e suas colaborações internacionais.

ILM: Em sua pesquisa você analisou não só a dança em Cuba, mas também dançarinos cubanos que trabalharam internacionalmente. Alguns, como Alberto Alonso, decidiram se

\footnotetext{
${ }^{6}$ BURDSALL, 2001.

7 GUILLERMOPRIETO, 2018.

${ }^{8}$ SCHWALL, 2017.

9 BURDSALL, 2001.
} 
exilar, principalmente nos Estados Unidos. Como aconteceram esses processos, qual foi a principal motivação para o exílio e que narrativas sobre a revolução elaboraram quando não mais moravam no país?

ES: Os dançarinos cubanos têm sido e continuam sendo muito móveis. Enquanto atuam, ensinam e coreografam no exterior, eles desenvolvem conexões que podem ajudar caso decidam deixar Cuba. Cada pessoa sai por motivos diferentes e, muitas vezes, uma única pessoa pode sair por uma combinação de razões políticas, econômicas, familiares ou profissionais. Independentemente disso, as conexões internacionais facilitam a migração e as carreiras no exterior.

Um exemplo dramático de abandono de bailarinos ocorreu em 1966, quando dez bailarinos pediram asilo enquanto se apresentavam em Paris. De acordo com a imprensa norte-americana, os dançarinos evitaram falar sobre ideologias políticas e, em vez disso, pediram asilo "cultural" ao fugir da perseguição ao inconformismo em Cuba ${ }^{10}$. Essa não conformidade pode ser na forma de política, roupas ou relações pessoais, especialmente ligações homossexuais. Os desertores do balé, todos homens, provavelmente, pelo menos em parte, fugiram da perseguição acelerada de homossexuais em Cuba no final dos anos $1960^{11}$. No entanto, como indica o comunicado de imprensa, eles não declararam necessariamente razões políticas anticomunistas para o seu asilo, mas sim as chamadas razões culturais.

Como outro exemplo, o coreógrafo Alberto Alonso foi para o exílio com sua esposa Sonia Calero e mudou a forma de narrar sua relação com o governo cubano. O processo começou em 1993, quando Alonso e Calero descobriram que seu filho havia fugido de jangada enquanto eles estavam no México trabalhando. Eles decidiram seguir seu filho para o exílio e acabaram trabalhando no Santa Fe Community College em Gainesville, Flórida. Uma vez nos Estados Unidos, Alonso narrou uma relação diferente com a Revolução daquela que teve ao longo de suas décadas em Cuba. Embora tenha criado obras com sentimentos revolucionários, como Conjugación (1970) sobre Che Guevara, nas décadas de 1990 e 2000 afirmou ter nutrido ressentimentos com o sistema e ter embutido a resistência antigovernamental em algumas de suas coreografias. Ele explicou a um público na Flórida que, no final dos anos 1960, estava chateado com os limites da expressão e que sua Carmen (1967) criticava metaforicamente o regime de Castro. ${ }^{12}$ De fato, outros confirmaram que

\footnotetext{
10 KENYON, 1966, p. D22.

11 GUERRA, 2012.

12 Alberto Alonso, discurso sem título, arquivo pessoal de Sonia Calero, Miami, Florida.
} 
Alonso encenou obras ousadas e polêmicas como Diógenes ante el tonel (1971), que o governo cubano efetivamente censurou ${ }^{13}$.

No entanto, Alonso não queria uma narrativa resistente para definir seu legado. Ricardo Acosta fez um documentário sobre sua vida, originalmente intitulado Dancing in Freedom's Shoes. O material promocional descreveu o filme após "uma incrível saga de triunfo sobre adversidades pessoais, artísticas e políticas". ${ }^{14}$ Alonso não gostou do nome e do enquadramento, e o filme foi rebatizado de Dança do Meu Coração. Este título menos combativo destacou um foco na história de amor entre Alonso e Calero, em vez de sua política $^{15}$. Em última análise, embora Alonso tenha falado mais livremente sobre sua dissidência política ao viver no exílio, sua saída de Cuba foi menos sobre ideologia e mais sobre desenvolvimentos pessoais e familiares (seu filho fugindo de jangada) e oportunidades (ele e Sonia no México), que combinou com as crescentes frustrações políticas e profissionais.

Muitos outros dançarinos cubanos começaram a sair na década de 1990 durante a crise econômica e política causada pela queda da União Soviética, o parceiro comercial mais importante de Cuba. Durante o chamado Período Especial, muitos dançarinos cubanos aproveitaram suas redes internacionais para desenvolver suas carreiras em outros lugares. ${ }^{16}$ A coreógrafa de dança moderna Marianela Boán fez pós-graduação nos Estados Unidos, mas acabou conseguindo um emprego construindo e dirigindo uma companhia na República Dominicana. Vários dançarinos contemporâneos cubanos acabaram em Chicago desde o início dos anos 2000, com os ex-membros da companhia Danza Contemporánea de Cuba, Victor Alexander Ramírez e Maray Gutiérrez, abrindo caminho para fora do acaso. Ou seja, eles foram inicialmente para Chicago porque Gutiérrez tinha família lá, e eles acabaram encontrando ótimas oportunidades para continuar dançando, ensinando e coreografando na cidade. Nos anos subsequentes, outros dançarinos contemporâneos cubanos seguiram seu caminho para Chicago na esperança de encontrar novos horizontes e oportunidades artísticas. Embora a política às vezes apareça nas histórias orais de vários jovens dançarinos cubanos atualmente em Chicago, talvez como uma piada improvisada sobre o sistema ou Fidel Castro, na maioria das vezes a política permanece completa ou quase inteiramente fora de suas narrativas.

Em resumo, as decisões de sair são complexas e idiossincráticas. A compreensão sobre o exílio, a migração e o que foi deixado para trás também muda com o tempo. É importante respeitar essas nuances, complexidades e mudanças.

\footnotetext{
${ }^{13}$ MARTÍNEZ, 2019.

14 Título original e materiais promocionais do arquivo pessoal de Sonia Calero, Miami, Florida.

${ }^{15}$ CALERO, 2013.

16 Olhar, por exemplo, o caso de Narciso Medina e outros discutidos em John 2012.
} 
ILM: Por fim, acredito, como pesquisador sobre Cuba e a cubanidade global, que um dos principais desafios é lidar com a dimensão política e os estereótipos dicotômicos que circulam sobre a Revolução Cubana. Você faz parte de uma nova geração de historiadores que atuou justamente como crítica dessa corrente, demonstrando a complexidade e as contradições que caracterizam Cuba. Você pode nos contar sobre esse processo?

ES: A Revolução recrutou artistas cubanos para contribuir com a construção de uma nova sociedade e muitos aderiram às campanhas revolucionárias. Alguns tinham convicções de esquerda e acreditavam no futuro socialista. Outros eram menos motivados politicamente, mas viram com precisão oportunidades sem precedentes para construir instituições, carreiras e públicos. Outros ainda, especialmente os nascidos na década de 1960 e depois, simplesmente iniciaram uma carreira sem pensar muito nas implicações sociais ou políticas mais amplas dessa escolha. Tentar honrar a multiplicidade de motivações que compelem os artistas cubanos ao longo do tempo continua sendo o maior desafio. Você está correto em notar que é fácil e comum caricaturar artistas cubanos como revolucionários ou contrarrevolucionários, servos do Estado ou dissidentes secretos. Na maioria dos casos, eles não eram nem são. Eles são artistas que operam em um contexto altamente politizado. Para tentar representar os bailarinos cubanos de forma mais holística, concentro-me em suas histórias sociais, pensando em seus salários e no acesso à alimentação, por exemplo. Também analiso como, junto com a ideologia, identidades sociais como gênero, raça e orientação sexual moldaram suas realidades. O exame de suas realizações, frustrações e esforços diários para sobreviver apresenta outra camada de experiência histórica, muitas vezes perdida por trás da politicagem da elite do regime.

\section{Referências}

BURDSALL, Lorna. More than Just a Footnote: Dancing from Connecticut to revolutionary Cuba. Quebec: AGMV Marquis, 2001.

CALERO, Sonia. Interview with Elizabeth Schwall, Miami, Florida. December 5, 2013.

DE LA FUENTE, Alejandro. A Nation for All: Race, Inequality, and Politics in Twentieth-Century Cuba. Chapel Hill: University of North Carolina Press, 2001.

GUERRA, Lillian. Visions of Power in Cuba: Revolution, Redemption, and Resistance, 1959-1971. Chapel Hill: University of North Carolina Press, 2012.

GUILLERMOPRIETO, Alma. La Habana en un espejo. Barcelona: Literatura Random House, 2018.

JOHN, Suki. Contemporary Dance in Cuba: Técnica Cubana as Revolutionary Movement. Jefferson, NC: McFarland, 2012.

KENYON, Kathryn. "Cuban Ballet's 'Giselle' Is Success Despite Defections." Los Angeles Times, November 17, 1966, p. D22.

LAMBE, Jennifer. Madhouse: Psychiatry and Politics in Cuban History. Chapel Hill: University of North Carolina Press, 2017. 
LEAL, Rine. Teatro Escambray. Havana: Editorial Letras Cubanas, 1978.

MARTíNEZ, Caridad. Interview with Elizabeth Schwall. New York City, New York. January 18, 2019.

MIRABAL, Elizabeth; VELAZCO, Carlos. Hablar de Guillermo Rosales. Miami: Editorial Silueta, 2013.

MOORE, Robin. Music and Revolution: Cultural Change in Socialist Cuba. Berkeley: University of California Press, 2006.

SCHWALL, Elizabeth. Coordinating Movements: The Politics of Cuban-Mexican Dance Exchanges, 1959-1983. Hispanic American Historical Review, v. 97, n. 4, p. 681-716, 2017.

SCHWALL, Elizabeth. A Spectacular Embrace: Dance Dialogues between Cuba and the Soviet Union, 1959-1973. Dance Chronicle, v. 41, n. 3, p. 275-302, 2018.

SERRA, Ana. The "New Man" in Cuba: Culture and Identity in the Revolution. Gainesville: University Press of Florida, 2007. 